\title{
Cancer stem cells as a therapeutic target in 3D tumor models of human chondrosarcoma: An encouraging future for proline rich polypeptide-1
}

\author{
CAROLINE J. GRANGER ${ }^{1}$, AARON K. HOYT ${ }^{1}$, ALEXANDRA MORAN ${ }^{1}$, BEATRICE BECKER $^{1 *}$, \\ ANIL SEDANI $^{1 *}$, SHANNON SAIGH ${ }^{2 *}$, SHEILA A. CONWAY ${ }^{1}$, JEFFREY BROWN ${ }^{1}$ and KARINA GALOIAN ${ }^{1}$ \\ ${ }^{1}$ RMSB Room 8012 (D27), Department of Orthopedic Surgery, University of Miami Miller School of Medicine; \\ ${ }^{2}$ Department of Medicine, Sylvester Comprehensive Cancer Center, Miami, FL 33136, USA
}

Received May 15, 2020; Accepted July 14, 2020

DOI: $10.3892 / \mathrm{mmr} .2020 .11480$

\begin{abstract}
Chondrosarcoma is a malignant bone neoplasm that is refractory to chemotherapy and radiation. With no current biological treatments, mutilating surgical resection is the only effective treatment. Proline rich polypeptide 1 (PRP-1), which is a 15-amino acid inhibitor of mammalian target of rapamycin complex-1 (mTORC1), has been indicated to exert cytostatic and immunomodulatory properties in human chondrosarcoma cells in a monolayer. The aim of the present study was to evaluate the effects of PRP-1 on an in vitro 3D chondrosarcoma tumor model, known as spheroids, and on the cancer stem cells (CSCs) which form spheroids. JJ012 cells were cultured and treated with PRP-1. An ALDEFLUOR ${ }^{\text {TM }}$ assay was conducted (with $\mathrm{N}, \mathrm{N}$-diethylaminobenzaldehyde as the negative control) to assess aldehyde dehydrogenase (ALDH) activity (a recognized CSC marker), and bulk JJ012, $\mathrm{ALDH}^{\text {high }}$ and PRP-1 treated ALDH ${ }^{\text {low }}$ cells were sorted using flow cytometry. Colony formation and spheroid formation assays of cell fractions, including CSCs, were used to compare the PRP-1-treated groups with the control. CSCs were assessed for early apoptosis and cell death with a modified Annexin V/propidium iodide assay. Western blotting was used to identify mesenchymal stem cell markers (STRO1, CD44 and STAT3), and spheroid self-renewal assays were also conducted. A clonogenic dose-response assay demonstrated that $20 \mu \mathrm{g} / \mathrm{ml}$ PRP-1 was the most effective dose for reducing colony formation capacity. Furthermore, CSC spheroid growth was significantly reduced with increasing doses of PRP-1.
\end{abstract}

Correspondence to: Dr Karina Galoian, RMSB Room 8012 (D27), Department of Orthopedic Surgery, University of Miami Miller School of Medicine, 1600 NW 10th Avenue, Miami, FL 33136, USA E-mail:kgaloian@med.miami.edu

*Contributed equally

Key words: chondrosarcoma, cancer stem cells, proline rich polypeptide-1, proline rich polypeptide 1 , spheroids
Annexin V analysis demonstrated that PRP-1 induced CSC cell death, and that this was not attributed to apoptosis or necrosis. Western blot analysis confirmed the expression of mesenchymal markers, and the spheroid self-renewal assay confirmed the presence of self-renewing CSCs. The results of the present study demonstrate that PRP-1 eliminates anchorage independent CSC growth and spheroid formation, indicating that PRP-1 likely inhibits tumor formation in a murine model. Additionally, a decrease in non-CSC bulk tumor cells indicates an advantageous decline in tumor stromal cells. These findings confirm that PRP-1 inhibits CSC proliferation in a 3D tumor model which mimics the behavior of chondrosarcoma in vivo.

\section{Introduction}

Chondrosarcoma is the second most common primary cartilage malignancy, accounting for 3.5-9\% of primary bone tumors and almost $30 \%$ of primary bone malignancies (1). These tumors affect one in every million individuals, and typically present in the 4 and 7th decades of life (2). Chondrosarcoma commonly presents as gradually progressive pain specific to the associated anatomical location (3). Axial tumors, the most common, are accompanied by a poorer prognosis and an increased rate of recurrence compared with acral tumors, and depending on the grade, are associated with a 10-year survival rate of $30-80 \%(4,5)$. Similarly, the presence of metastasis worsens prognosis, and metastases frequently arise in the lungs as a result of hematogenous dissemination (6,7). Local tumor recurrence is common, and adjuvant radio- and chemotherapy are largely ineffective; thus despite significant morbidity, local excision has become an increasingly popular treatment method, even for low grade lesions $(4,8,9)$. A notable limitation to existing management strategies is that chondrosarcomas are impervious to chemotherapy and radiation, a characteristic largely attributed to the presence of drug-resistant cancer stem cells (CSCs) in the neoplastic ecosystem $(2,10,11)$.

It has recently been established that transformed mesenchymal stem cells, or their immediate precursors, are the most likely cellular origin of chondrosarcoma (12). The CSC theory is based on experimental evidence that undifferentiated 
CSCs exist and function to maintain the bulk population of cells within a tumor, sustaining the cancer and allowing for recurrence and metastasis (11). They share several key characteristics with non-neoplastic stem cells, including self-renewal and asymmetric division, the hallmark properties of cancer cells $(13,14)$.

Identifying and isolating CSCs in vitro has been historically challenging, but was largely overcome by the use of tumor-derived spheroids $(15,16)$. Spheroids act as surrogate systems to evaluate and manipulate the CSC-associated properties of solid tumors, including tumor resistance to chemotherapy and radiation, sustaining the cancer, recurrence, and metastasis (17). Experimentally, spheroids are particularly important in sarcoma research, as their growth rates, cellular morphology, cell-cell junctional behavior and kinase activation properties (to name a few) closely mimic those of primary tumors (10). Additionally, spheroids are a useful model of micrometastatic disease. Tumor-derived spheroids are generally comprised of three structural layers: i) A central core of hypoxic, starved necrotic cells; ii) an inner layer of nonproliferating quiescent CSCs; and iii) an outer nutrient-rich layer of proliferating tumor stromal cells, which interact with the surrounding extracellular matrix $(10,18)$.

Given that the chemoresistance and tumorigenicity of chondrosarcomas are attributed to the CSC population, targeting CSCs is of great significance in the realm of biologic or chemotherapeutic management (19). The aforementioned resistance to electromagnetic and chemical insult is partly conferred by the infrequent replication of CSCs and their heightened activation of DNA repair mechanisms (and therefore, a lower apoptotic rate), an active drug efflux system, and increased defenses against reactive oxygen species $(13,14,20)$. As such, CSCs are considered to be responsible for recurrence following radiation and resection therapy, and are chiefly accountable for tumor metastasis (21). CSCs create a resilient and self-propagating tumor microenvironment, which in combination with a matrix, functions to impair drug diffusion, further contributing to chemoresistance $(10,20)$. Though treatments that inhibit CSC proliferation have been described in other types of sarcoma, there are currently no methods for impeding CSCs in chondrosarcoma (22). Furthermore, the behavior of spheroids in chondrosarcoma has not been fully elucidated. Therefore, the identification of novel agents which successfully target CSCs is essential for improving the clinical management and prognosis of chondrosarcoma.

Proline rich polypeptide-1 (PRP-1), an antitumorigenic cytokine, is a fragment of the neurophysin-vasopressinassociated glycoprotein that is produced by hypothalamic neurosecretory cells. The primary structure of PRP-1 (isolated from neurosecretory granules of bovine neurohypophysis) comprises 15 amino acids (Ala-Gly-Ala-Pro-Glu-Pro-Ala-Gl u-Pro-Ala-Gln-Pro-Gly-Val-Tyr) with an apparent molecular mass of 1.475 Daltons. PRP-1 has also been described as a potent immunomodulator which inhibits mTOR and cMyc, and suppresses cell cycle progression in high grade chondrosarcoma (23-27). A unique feature of this potential biologic agent is its physiological presence in the human body (28). PRP-1 is released into systemic circulation and has multiple organotrophic functions, including mediating the hypothalamus-neurohypophysis-bone marrow axis, as well as other immunomodulatory functions $(25,29)$.

Given the lack of a dependable treatment and an overwhelmingly poor prognosis, identification of novel therapies for chondrosarcoma is a critical clinical priority. The efficiency by which PRP-1 eliminates CSCs has been previously described in a monolayer, and was flow cytometrically determined to result from the aldehyde dehydrogenase $(\mathrm{ALDH})^{\text {high }}$ population of the chondrosarcoma monolayer, in association with the antineoplastic regulation of aberrant $\mathrm{Wnt} / \beta$-catenin signaling (30). Likewise, PRP-1 was also found to exert cytostatic properties in a chondrosarcoma monolayer by promoting cell cycle arrest in the $\mathrm{S}$ phase (26). This prompted further investigation into the effects of PRP-1; specifically, the ability to eliminate anchorage independent colony formation (a symbol of malignancy) and 3D chondrosarcoma stem cell spheroid formation (a hallmark of the metastatic abilities of CSC metastasis, recurrence, cancer sustainability, and chemo- and radio-resistance). The present study utilizes a novel in vitro 3D tumor model, (chondrosarcoma spheroids) to determine the effects of PRP-1 on the human chondrosarcoma CSC population.

\section{Materials and methods}

Establishing 2D and 3D cultures of chondrosarcoma JJ012 cells. 2D cell cultures were established in T-175 flasks (353112, Falcon) and grown in $37^{\circ} \mathrm{C}, 5 \% \mathrm{CO}_{2}$ incubator for two days to achieve $80 \%$ confluency. Mycoplasma testing was completed for the cell lines used in all experiments, the cell lines used were authenticated, and cell culture lines were maintained according to international guidelines on good cell culture practice. Upon trypsinization, centrifuged cells were pushed through $40 \mu \mathrm{m}$ cell strainer (431750, Corning) to ensure a healthy single cell suspension. 3D cultures were established by seeding cells at an optimized density of 500,000 cells/well in 6-well low attachment plates (3471, Corning) in Advanced DMEM/F-12 media with reduced Fetal Bovine Serum (12634028, Thermo Fisher Scientific, Inc.), supplemented with $10 \mathrm{ng} / \mathrm{ml}$ basic fibroblast growth factor (AF-100-18C, Peprotech), $10 \mathrm{ng} / \mathrm{ml}$ epidermal growth factor (AF-100-15, Peprotech), and $10 \mathrm{ul} / \mathrm{ml}$ N2 supplement (17502048, Thermo Fisher Scientific, Inc.). Additional human epidermal growth factor $(10 \mathrm{ng} / \mathrm{ml})$ and human basic fibroblast growth factor $(10 \mathrm{ng} / \mathrm{ml})$ were added to each well every other day. Sarcosphere growth was observed every day for 5-6 days and colonies were imaged on day 6 on Leica DMI3000 B Inverted Microscope.

Aldefluor $^{\circledR}$ assay and fluorescence-activated cell sorting (FACS). For the following experiment, we followed the methods of our previous study, Hoyt et al (30). To measure cells with ALDH activity, the Aldefluor ${ }^{\circledR}$ assay was carried out as described according to manufacturer's protocol (Aldefluor kit, cat. no. 01700; StemCell Technologies). Briefly, cells were harvested and resuspended in Aldefluor assay buffer at a concentration of $1 \times 10^{6} / \mathrm{ml}$. To activate the Aldefluor reagent, first $25 \mu \mathrm{l}$ of DMSO was added and incubated for 15 min with $25 \mu \mathrm{l}$ of $2 \mathrm{~N} \mathrm{HCl}$, then $360 \mu \mathrm{l}$ of assay buffer was added to the vial. The cells were then incubated with the activated Aldefluor reagent for $45 \mathrm{~min}$ at $37^{\circ} \mathrm{C}$. Diethylaminobenzaldehyde (DEAB), a specific ALDH inhibitor, was added as a negative control. 
Following incubation, all tubes were centrifuged for $5 \mathrm{~min}$ at $250 \mathrm{x} \mathrm{g}$, and the supernatant was removed, and resuspended in Aldefluor assay buffer. The cells were then transferred and strained onto Falcon $5 \mathrm{ml}$ polystyrene round bottom tube with a cell strainer cap (cat. no. 352235). After labeling, the samples were sorted on a BD Biosciences Special Order Research Product (SORP) FACSAria II, using BD FACSDiva software (version 6.1.3) into $\mathrm{ALDH}^{\text {low }}$ and $\mathrm{ALDH}^{\text {high }}$ cells with and without PRP-1 treatment. Data analysis was performed using FlowJo software (FlowJo LLC) (version 10).

\section{Anchorage-independent cell colony growth assay (31)}

Production of $3 \%$ agarose solution. Under the hood and in a sterile $50 \mathrm{ml}$ falcon tube, $0.9 \mathrm{~g}$ agar powder was dissolved in $30 \mathrm{ml}$ distilled water in duplicate to reach a total volume of $60 \mathrm{ml} \mathrm{3 \%}$ agar. Sterile $3 \%$ agar solution was placed in a $45^{\circ} \mathrm{C}$ water bath to keep solution in liquid phase.

Production of the bottom layer (0.6\% Agarose Gel). Pipette tips $(10 \mathrm{ml})$ were pre-warmed in incubator to prevent agarose from solidifying with handling and $9 \mathrm{ml}$ of $3 \%$ agarose solution was transferred into a sterile $50 \mathrm{ml}$ conical tube, then $36 \mathrm{ml}$ warm JJ012 media was added with the tube mixed by inversion. $2 \mathrm{ml}$ of this mixture was gently added into 14 wells of three 6-well culture plates three times for a total of 42 wells and nine plates while avoiding bubble formation. Plates were incubated horizontally on a flat surface at $4^{\circ} \mathrm{C}$ for $301 \mathrm{~h}$ to allow the mixture to solidify, then plates were placed in a $37^{\circ} \mathrm{C}$ incubator for $30 \mathrm{~min}$.

Preparation of cell suspension layer. JJ012 cells and ALDH-tagged fractions were harvested and diluted in media to a cell concentration of $5 \times 10^{5}$ cells $/ \mathrm{ml}$ to be seeded in each well of three 6 well plates per cell group. $0.6 \%$ Agarose was prepared by mixing $6 \mathrm{ml}$ of 3\% agarose with $24 \mathrm{ml} \mathrm{JJ012}$ media by inversion while avoiding bubble formation. Each well was treated according to its assignment in a dose response manner. In a 1:1 dilution, $500 \mu \mathrm{l}$ cell suspension containing $5 \times 10^{5}$ cells $/ \mathrm{ml}$ were mixed with $0.6 \%$ agarose solution. $1 \mathrm{ml}$ of the cell-agarose solution was subsequently added to the bottom layer of the 6-well culture plates to achieve a seeding concentration of $2.5 \times 10^{5}$ cells $/ \mathrm{ml}$. Plates were incubated at $4^{\circ} \mathrm{C}$ for $15 \mathrm{~min}$ to allow the top cell layer to solidify and then moved to a $37^{\circ} \mathrm{C}$ incubator for 1 week.

Production of the feeder layer: $0.3 \%$ agarose gel. Pre-made $3 \%$ agarose solution was heated and mixed with warm JJ012 media by inversion to create one mixture for control cells and one for each PRP-1 treatment group. The treatment mixture was treated with the respective concentration of PRP-1 and $1 \mathrm{ml}$ of the mixture was added to the designated wells of each 6-well culture plate containing the bottom and cell layers. Plates were placed at $4^{\circ} \mathrm{C}$ for $15 \mathrm{~min}$ to allow the mixture to solidify and then moved to a $37^{\circ} \mathrm{C}$ incubator. The feeding procedure was repeated weekly for 3 weeks. Cell colonies were counted using a light microscope and imaged with an inverted microscope at 400 and $100 \mu \mathrm{m}$.

Dose response sarcosphere formation assay $(32,33)$. Human chondrosarcoma JJ012 cells were cultured in a monolayer, then harvested with trypsin and neutralized with serum-containing media. Cells were subsequently centrifuged and resuspended with Thermo-Fischer Advanced (Serum-free) DMEM/F12 (Cat\#12634028). Cells were centrifuged again and resuspended in $5 \mathrm{ml}$ round bottom polystyrene test tubes through a strainer cap to ensure a healthy single cell suspension.

Cells were then counted and plated in Corning Costar Ultra-Low Attachment 6-Well Plates (Sigma-Aldrich; Merck KGaA cat\# CLS3471) at a density of 500,000 cells/well with serum-free DMEM/F12 medium with $10 \mathrm{ng} / \mathrm{ml}$ basic fibroblast growth factor, $10 \mathrm{ng} / \mathrm{ml}$ epidermal growth factor, and $10 \mu \mathrm{l} / \mathrm{ml} \mathrm{N} 2$ supplement. Cells were treated with PRP-1 daily, in duplicate, and in a dose-dependent manner of control, $0.05 \mu \mathrm{g} / \mathrm{ml}$ PRP-1, $0.5 \mu \mathrm{g} / \mathrm{ml}$ PRP-1, $1 \mu \mathrm{g} / \mathrm{ml}$ PRP-1, $5 \mu \mathrm{g} / \mathrm{ml}$ PRP-1, $10 \mu \mathrm{g} / \mathrm{ml}$ PRP-1, $20 \mu \mathrm{g} / \mathrm{ml}$ PRP-1. Additional human epidermal growth factor $(10 \mathrm{ng} / \mathrm{ml})$ and human basic fibroblast growth factor $(10 \mathrm{ng} / \mathrm{ml})$ were added to the media in each well every other day. Colonies were imaged after 7 days using inverted phase contrast microscopy at x40 magnification. Images were captured in 5 fields of view for each well. Spheroids were quantified by two separate investigators (CG, AM) at two separate occurrences counting spheroid number over 5 randomly selected high-powered fields and calculating a mean value. Discrepancies regarding the mean were re-counted by both investigators until equal values were calculated by both investigators to ensure reporting of true values only.

Gel electrophoresis and western blot. JJ012 chondrosarcoma cells were cultured and incubated to confluency. Cells were collected using trypsin and then seeded into Petri dishes at a concentration of $1 \times 10^{6}$ cells $/ \mathrm{ml}$. The cells were incubated for $24 \mathrm{~h}$ at $37^{\circ} \mathrm{C}$ in a $5 \% \mathrm{CO}_{2}$ incubator. The next day, an ice-cold phosphate-buffered saline wash was performed, and protease inhibitor was added to the cell lysis buffer (C2978; Sigma-Aldrich; Merck KGaA) in a 1:100 ratio. After harvesting cells with a rubber scraper and lysis of cell membranes with an 18-gauge needle, the cells were centrifuged at 15,000 $\mathrm{x} \mathrm{g}$ at $4^{\circ} \mathrm{C}$. The supernatant was then collected, and protein content was measured using NanoDrop ${ }^{\circledR}$ spectrophotometer (Thermo Fisher Scientific, Inc.). The supernatant was frozen at $-80^{\circ} \mathrm{C}$ until loading onto the gels $(20 \mu \mathrm{g} /$ lane $)$. Polyacrylamide gel electrophoresis and western blotting reagents were supplied by Lonza, Inc. and related procedures were followed in accordance with the company's protocol. The catalog numbers for the reagents and suppliers are listed below. Pager Gold Precast Gels (59502; 10\% Tris-glycine; Lonza, Inc.); ECL reagent (RPN2109; GE Healthcare); Western Blocker solution (W0138; Sigma-Aldrich; Merck KGaA); ProSieve Quad Color Protein marker (4.6-300 kDa, 00193837; Lonza, Inc.); 20X reducing agent for ProSieve ProTrack Dual Color Loading buffer (00193861; Lonza, Inc.); ProTrack loading buffer (00193861; Lonza, Inc.); ProSieve ProTrack Dual Color Loading buffer EX running buffer (00200307; Lonza, Inc.); ProSieve EX Western Blot Transfer buffer (00200309; Lonza, Inc.); Immobilon ${ }^{\circledR}$-P polyvinylidene difluoride membranes (P4188; Sigma-Aldrich; Merck KGaA).

Antibodies for western blotting. Mouse monoclonal antibody to CD44 was applied as a primary antibody (Sigma-Aldrich; 


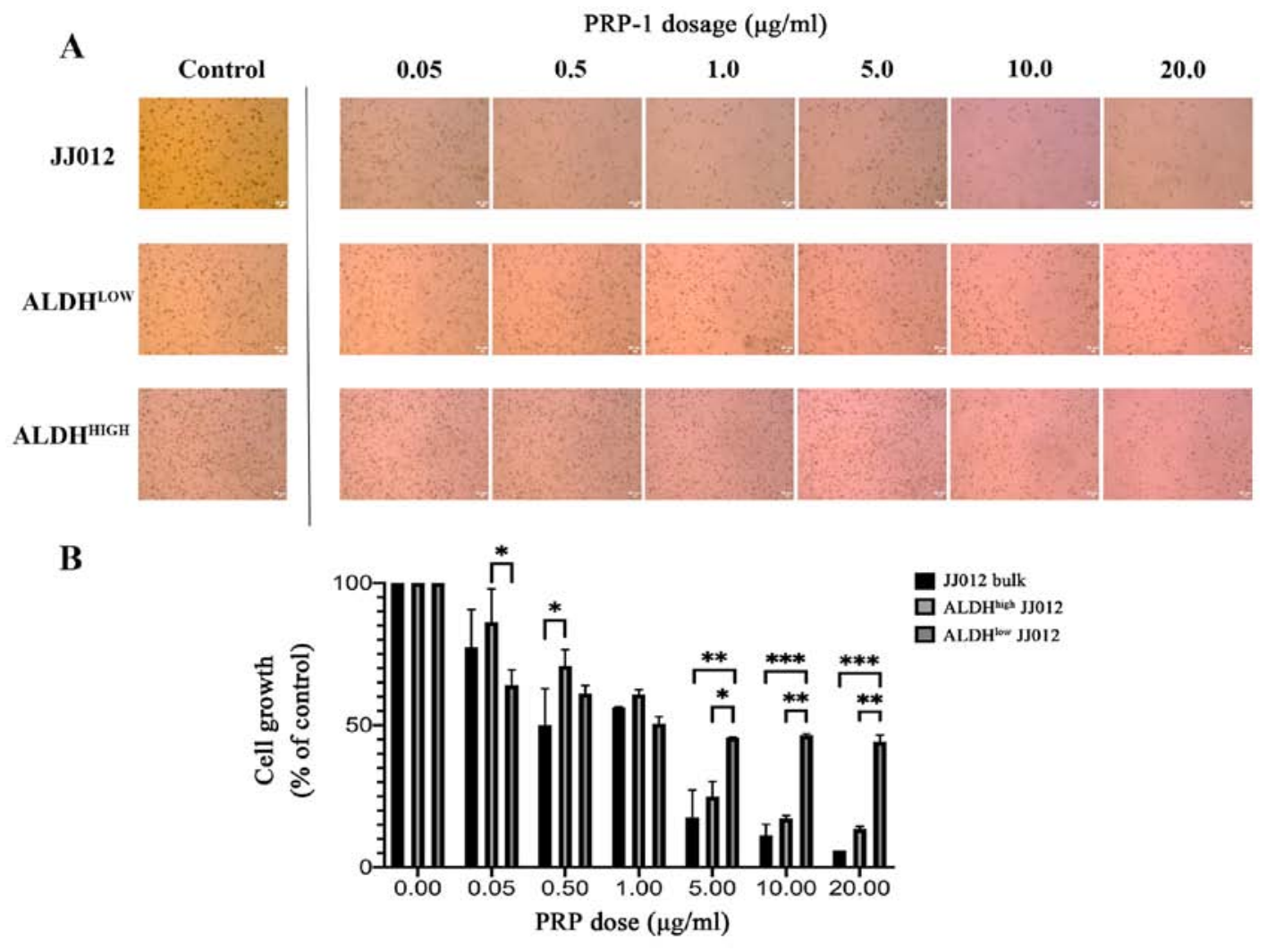

C

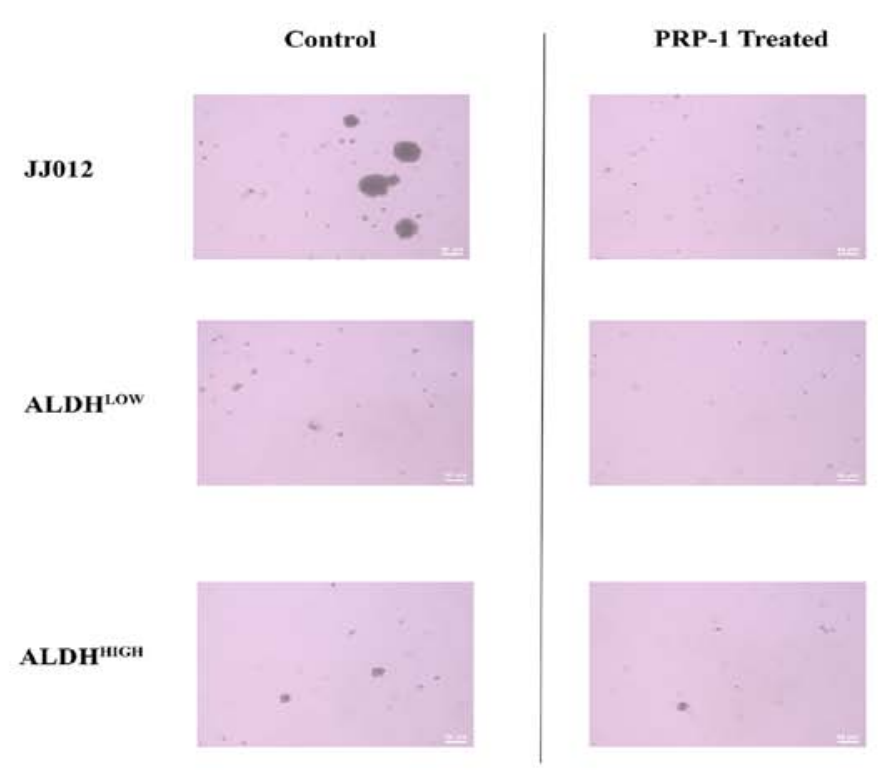

Figure 1. Dose response cell colony formation of chondrosarcoma population fractions. (A) Qualitative cell colony formation following PRP-1 treatment in bulk JJ012, stromal ALDH ${ }^{\mathrm{LOW}}$ population, and CSC ALDH ${ }^{\mathrm{HIGH}}$ population as described in methods. (B) Dose response data graphically reflecting post-hoc Tukey data from two-way ANOVA on the same cell populations as reflected in (A). ${ }^{*} \mathrm{P}<0.01 ;{ }^{* * *} \mathrm{P}<0.001 ;{ }^{* * * *} \mathrm{P}<0.0001$. (C) Comparison of control cell colonies to maximally reduced cell colony samples following treatment with PRP-1. PRP-1, Proline rich polypeptide 1; ALDH, aldehyde dehydrogenase; CSC, cancer stem cell.

Merck KGaA, SAB1402714) at a dilution of 1:1,000 and goat anti-mouse $\mathrm{IgG}$ peroxidase conjugate as a secondary antibody (A4416; Sigma-Aldrich; Merck KGaA) at a dilution of 1:5,000. Mouse monoclonal antibody to STRO-1 was applied as a primary antibody (Life Technologies, 398401) at a dilution of 1:250 and secondary antibody (A4416; Sigma-Aldrich; Merck KGaA) at a dilution of 1:5,000. Mouse monoclonal antibody to STAT3 was added as a primary antibody (Santa
Cruz Biotechnology, sc-293151) at a dilution of 1:1,000 and secondary antibody (A4416; Sigma-Aldrich; Merck KGaA) at a dilution of 1:5,000. As housekeeping proteins, mouse anti-tubulin antibody was used (T5168; Sigma-Aldrich; Merck $\mathrm{KGaA}$ ) at a dilution of 1:2,000 and anti-mouse IgG (A4416; Sigma-Aldrich; Merck KGaA) at a dilution of 1:5,000 was applied as a secondary antibody. Incubations for all primary antibodies were carried out in a cold room while rocking for a 


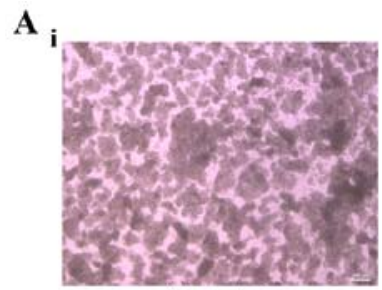

$0.0(\mu \mathrm{g} / \mathrm{ml})$

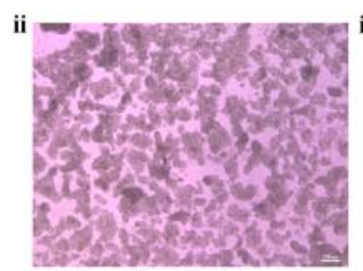

$0.05(\mu \mathrm{g} / \mathrm{ml})$

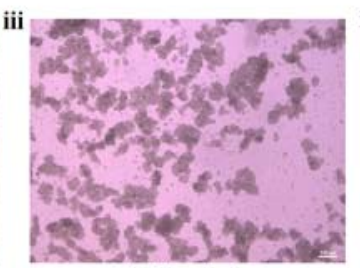

$0.5(\mu \mathrm{g} / \mathrm{ml})$

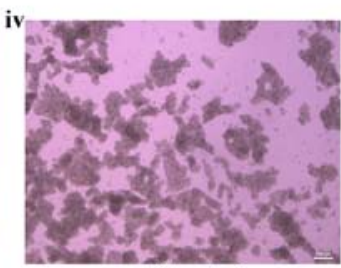

$1.0(\mu \mathrm{g} / \mathrm{ml})$

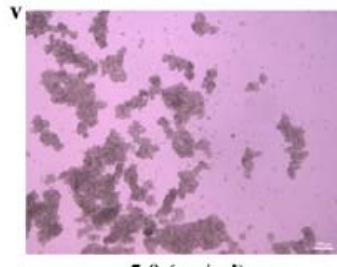

$5.0(\mu \mathrm{g} / \mathrm{ml})$

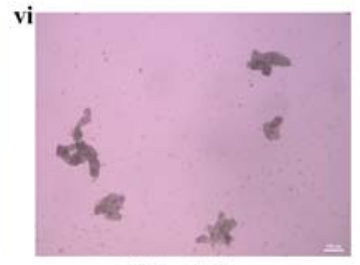

$10(\mu \mathrm{g} / \mathrm{ml})$

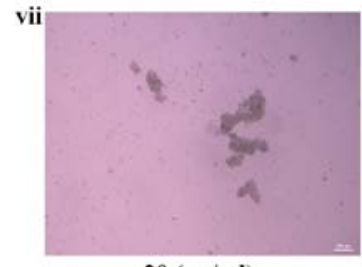

$20(\mu \mathrm{g} / \mathrm{ml})$

B

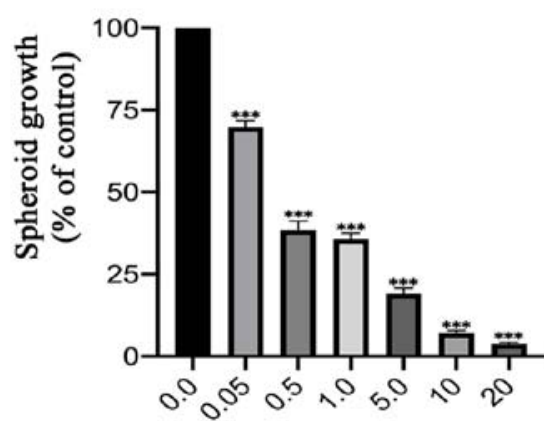

PRP-1 dose $(\mu \mathrm{g} / \mathrm{ml})$

Figure 2. Dose-response chondrosarcoma spheroid formation assay. (A) Qualitative spheroid formation following PRP-1 treatment using the specified doses with light microscopy at $\mathrm{x} 40$. (B) Dose response data graphically representing one-way ANOVA of spheroid growth measured as number of spheroids grown. ${ }^{* * * *} \mathrm{P}<0.0001$.

period of $24 \mathrm{~h}$, while secondary antibodies were incubated for $2 \mathrm{~h}$ under the same conditions.

Self-renewal assay (21). Cultured 3D sarcospheres were dissociated into single-cell suspensions and inoculated into medium without serum in T-175 flasks (353112, Falcon) to ensure only cells from spheroids would propagate and allowed to grow in 2D monolayers for approximately 2 days. At near $80 \%$ confluency, cells were harvested and reseeded as single cells and plated at a density of 500,000 cells/well in 6-well ultra-low attachment plates (3471, Corning) and in 150x15 mm Petri Dishes (351058, Falcon) in Advanced DMEM/F-12 media with reduced Fetal Bovine Serum (12634028, Thermo Fisher Scientific, Inc.), supplemented with $10 \mathrm{ng} / \mathrm{ml}$ basic fibroblast growth factor, $10 \mathrm{ng} / \mathrm{ml}$ epidermal growth factor, and $10 \mu \mathrm{l} / \mathrm{ml}$ N2 supplement. Additional human epidermal growth factor $(10 \mathrm{ng} / \mathrm{ml})$ and human basic fibroblast growth factor $(10 \mathrm{ng} / \mathrm{ml})$ were added to each well of the 6-well plates every other day, but not added to petri dishes. Sarcosphere growth was observed every day for 5-6 days and colonies were imaged on day 6 on Confocal Leica TCS SP5 microscope using x10 and x20 objective lenses.

Modified Annexin VIPI apoptosis assay (invitrogen eBioscience Annexin V apoptosis detection Kit APC; Cat \#88-8007-72) (34) Cell preparation. Human chondrosarcoma JJ012 cells were grown in a monolayer, harvested, and centrifuged at $335 \mathrm{x} \mathrm{g}$ for $10 \mathrm{~min}$. Cells were resuspended in $2 \mathrm{ml} 1 \mathrm{x}$ phosphate buffered saline (PBS) and samples were centrifuged at $335 \mathrm{x}$ g for $10 \mathrm{~min}$. Cells were then resuspended in $1 \mathrm{ml} 1 \mathrm{X}$ Annexin V binding buffer. The resuspended pellets were centrifuged at $335 \mathrm{x}$ g for $10 \mathrm{~min}$. Finally, pellets were resuspended in $100 \mu \mathrm{l}$ 1X Annexin V binding buffer.

Application of Annexin V/Pi stain. Annexin V was added according to the manufacturer's recommendations. Tubes were incubated in the dark for $15 \mathrm{~min}$ at room temperature. $1 \mathrm{X}$ Annexin $\mathrm{V}$ binding buffer $(100 \mu \mathrm{l})$ was added to each reaction tube to allow for a volume of $200 \mu \mathrm{l}$ in each tube. PI $(4 \mu \mathrm{l})$ (Sigma-Aldrich; Merck KGaA, cat \# P-4864-10ML), diluted 1:10 in $1 \mathrm{X}$ Annexin $\mathrm{V}$ binding buffer, was then added to yield a final PI concentration of $2 \mu \mathrm{g} / \mathrm{ml}$ in each sample. Tubes were incubated in the dark for $15 \mathrm{~min}$ at room temperature. 1X Annexin V binding buffer (500 $\mu \mathrm{l})$ was added to wash the cells. Samples were centrifuged at $335 \mathrm{x}$ g for $10 \mathrm{~min}$. Pellets were resuspended in $500 \mu \mathrm{l} 1 \mathrm{X}$ Annexin $\mathrm{V}$ binding buffer and $500 \mu \mathrm{l} 2 \%$ formaldehyde to create a $1 \%$ formaldehyde (fixative) solution. Tubes were mixed by gentle flicking and samples then fixed on ice for $10 \mathrm{~min}$. 1X PBS $(1 \mathrm{ml})$ was added to each sample and mixed gently by flicking. The suspension was then centrifuged at $425 \mathrm{x}$ g for $8 \mathrm{~min}$. Centrifugation and resuspension steps were repeated twice, and pellet was finally resuspended by flicking the tube. Following resuspension, $16 \mu \mathrm{l}$ of 1:100 diluted RNase A (Sigma-Aldrich; Merck KGaA, 
Table I. Post Hoc Tukey's analysis of dose response cell colony growth.

\begin{tabular}{|c|c|c|c|}
\hline Comparison & Mean difference & $95 \%$ confidence interval of difference & P-value \\
\hline \multicolumn{4}{|l|}{ JJ012 Bulk } \\
\hline 0.0 vs. 0.05 & 22.50 & -4.057 to 49.05 & 0.1331 \\
\hline 0.0 vs. 0.5 & 49.97 & 23.41 to 76.52 & $<0.0001$ \\
\hline 0.0 vs. 1.0 & 43.75 & 17.19 to 70.30 & 0.0004 \\
\hline 0.0 vs. 5.0 & 82.40 & 55.85 to 109.0 & $<0.0001$ \\
\hline 0.0 vs. 10 & 88.73 & 62.18 to 115.3 & $<0.0001$ \\
\hline 0.0 vs. 20 & 94.11 & 67.55 to 120.7 & $<0.0001$ \\
\hline 0.05 vs. 0.5 & 27.47 & 0.9183 to 54.02 & 0.0395 \\
\hline 0.05 vs. 1.0 & 21.25 & -5.302 to 47.80 & 0.1754 \\
\hline 0.05 vs. 5.0 & 59.91 & 33.35 to 86.46 & $<0.0001$ \\
\hline 0.05 vs. 10 & 66.24 & 39.68 to 92.79 & $<0.0001$ \\
\hline 0.05 vs. 20 & 71.61 & 45.06 to 98.16 & $<0.0001$ \\
\hline 0.5 vs. 1.0 & -6.220 & -32.77 to 20.33 & 0.9863 \\
\hline 0.5 vs. 5.0 & 32.44 & 5.883 to 58.99 & 0.0105 \\
\hline 0.5 vs. 10 & 38.77 & 12.21 to 65.32 & 0.0018 \\
\hline 0.5 vs. 20 & 44.14 & 17.59 to 70.69 & 0.0004 \\
\hline 1.0 vs. 5.0 & 38.66 & 12.10 to 65.21 & 0.0019 \\
\hline 1.0 vs. 10 & 44.99 & 18.43 to 71.54 & 0.0003 \\
\hline 1.0 vs. 20 & 50.36 & 23.81 to 76.91 & $<0.0001$ \\
\hline 5.0 vs. 10 & 6.330 & -20.22 to 32.88 & 0.9850 \\
\hline 5.0 vs. 20 & 11.71 & -14.85 to 38.26 & 0.7785 \\
\hline 10 vs. 20 & 5.375 & -21.18 to 31.93 & 0.9936 \\
\hline \multicolumn{4}{|l|}{ aldh $^{\text {high }}$ jj012 } \\
\hline 0.0 vs. 0.05 & 13.75 & -12.80 to 40.30 & 0.6334 \\
\hline 0.0 vs. 0.5 & 29.14 & 2.591 to 55.69 & 0.0255 \\
\hline 0.0 vs. 1.0 & 39.16 & 12.60 to 65.71 & 0.0016 \\
\hline 0.0 vs. 5.0 & 75.15 & 48.60 to 101.7 & $<0.0001$ \\
\hline 0.0 vs. 10 & 82.81 & 56.25 to 109.4 & $<0.0001$ \\
\hline 0.0 vs. 20 & 86.49 & 59.94 to 113.0 & $<0.0001$ \\
\hline 0.05 vs. 0.5 & 15.39 & -11.16 to 41.94 & 0.5109 \\
\hline 0.05 vs. 1.0 & 25.40 & -1.147 to 51.96 & 0.0667 \\
\hline 0.05 vs. 5.0 & 61.40 & 34.85 to 87.95 & $<0.0001$ \\
\hline 0.05 vs. 10 & 69.06 & 42.50 to 95.61 & $<0.0001$ \\
\hline 0.05 vs. 20 & 72.74 & 46.19 to 99.29 & $<0.0001$ \\
\hline 0.5 vs. 1.0 & 10.01 & -16.54 to 36.56 & 0.8763 \\
\hline 0.5 vs. 5.0 & 46.01 & 19.45 to 72.56 & 0.0002 \\
\hline 0.5 vs. 10 & 53.66 & 27.11 to 80.21 & $<0.0001$ \\
\hline 0.5 vs. 20 & 57.35 & 30.80 to 83.90 & $<0.0001$ \\
\hline 1.0 vs. 5.0 & 35.99 & 9.443 to 62.55 & 0.0039 \\
\hline 1.0 vs. 10 & 43.65 & 17.10 to 70.20 & 0.0005 \\
\hline 1.0 vs. 20 & 47.34 & 20.79 to 73.89 & 0.0002 \\
\hline 5.0 vs. 10 & 7.656 & -18.90 to 34.21 & 0.9618 \\
\hline 5.0 vs. 20 & 11.34 & -15.21 to 37.90 & 0.8015 \\
\hline 10 vs. 20 & 3.688 & -22.86 to 30.24 & 0.9992 \\
\hline \multicolumn{4}{|l|}{ aldh $^{\text {low }}$ jj012 } \\
\hline 0.0 vs. 0.05 & 35.91 & 9.358 to 62.46 & 0.0040 \\
\hline 0.0 vs. 0.5 & 38.79 & 12.24 to 65.34 & 0.0018 \\
\hline 0.0 vs. 1.0 & 49.53 & 22.98 to 76.08 & $<0.0001$ \\
\hline 0.0 vs. 5.0 & 54.38 & 27.82 to 80.93 & $<0.0001$ \\
\hline 0.0 vs. 10 & 53.53 & 26.97 to 80.08 & $<0.0001$ \\
\hline 0.0 vs. 20 & 55.84 & 29.28 to 82.39 & $<0.0001$ \\
\hline 0.05 vs. 0.5 & 2.880 & -23.67 to 29.43 & 0.9998 \\
\hline
\end{tabular}


Table I. Continued.

\begin{tabular}{lccr}
\hline Comparison & Mean difference & 95\% confidence interval of difference & P-value \\
\hline 0.05 vs. 1.0 & 13.62 & -12.93 to 40.17 & 0.6431 \\
0.05 vs. 5.0 & 18.47 & -8.087 to 45.02 & 0.3073 \\
0.05 vs. 10 & 17.62 & -8.937 to 44.17 & 0.3583 \\
0.05 vs. 20 & 19.93 & -6.627 to 46.48 & 0.2314 \\
0.5 vs. 1.0 & 10.74 & -15.81 to 37.29 & 0.8376 \\
0.5 vs. 5.0 & 15.59 & -10.97 to 42.14 & 0.4969 \\
0.5 vs. 10 & 14.74 & -11.82 to 41.29 & 0.5597 \\
0.5 vs. 20 & 17.05 & -9.507 to 43.60 & 0.3950 \\
1.0 vs. 5.0 & 4.845 & -21.71 to 31.40 & 0.9963 \\
1.0 vs. 10 & 3.995 & -22.56 to 30.55 & 0.9987 \\
1.0 vs. 20 & 6.305 & -20.25 to 32.86 & 0.9853 \\
5.0 vs. 10 & -0.8500 & -27.40 to 25.70 & $>0.9999$ \\
5.0 vs. 20 & 1.460 & -25.09 to 28.01 & $>0.9999$ \\
10 vs. 20 & 2.310 & -24.24 to 28.86 & $>0.9999$ \\
\hline
\end{tabular}

$\mathrm{R} 4642$ ) was added to provide a final concentration of $50 \mu \mathrm{g} / \mathrm{ml}$. Samples were incubated for $15 \mathrm{~min}$ at $37^{\circ} \mathrm{C}$. $1 \mathrm{X}$ PBS $(1 \mathrm{ml})$ and mixed gently by flicking. Tubes were centrifuged at $425 \mathrm{x} g$ for eight minutes. Samples were then taken for flow cytometric analysis. Data analysis was performed using FlowJo software (FlowJo LLC) (version 10).

Statistics. Statistical analyses were performed using two-way analysis of variance (ANOVA) with a post hoc Tukey's multiple comparisons test to determine cell colony growth differences at each PRP-1 dose between cell groups and within each cell group between PRP-1 doses. One-way analysis of variance (ANOVA) with a post hoc Tukey's multiple comparisons test was used to determine differences in spheroid growth at each PRP-1 dose. Post hoc analysis expressed as a 95\% confidence interval of the mean difference. Spheroid growth experiments were repeated 2 times. Densitometric analysis was obtained using density analysis on Image $(\mathrm{NIH})$ to calculate relative optical density (OD) of antibodies in comparison to the housekeeping protein, $\alpha$-tubulin, and bulk untreated-JJ012 was used as control. Statistical analyses of relative optical densities were performed using individual unpaired t-tests of all samples expressed with a $95 \%$ confidence interval of the mean difference of relative OD. All statistical analyses were completed using GraphPad Prism 8.3.0 (GraphPad Software, Inc.). A P-value $<0.05$ was considered significant. Error bars represent standard error of the mean (SEM) in all graphs with ${ }^{*} \mathrm{P}<0.05,{ }^{* *} \mathrm{P}<0.01,{ }^{* * *} \mathrm{P}<0.001$ (as indicated in the figures and figure legends).

\section{Results}

PRP-1 significantly decreases colony formation and anchorage independent growth in human chondrosarcoma. The antitumorigenic effects of PRP-1 on bulk, a term which designates tumor stromal chondrosarcoma cell monolayers, has previously been established, including the antineoplastic regulation of the Wnt/ $\beta$-catenin pathway (30); this prompted further investigation into the role of PRP-1 on anchorage independent growth. To ensure the specific investigation of anchorage independent growth, cell colonies were cultivated using an agarose colony formation assay known to involve anchorage independence and necessitate CSC involvement as a prerequisite (31). Qualitative analysis revealed a decrease in colony viability following treatment with PRP-1 (Fig. 1A and C). Two-way ANOVA was conducted to determine the effects of cellular population and PRP-1 dose on spheroid growth (Fig. 1B). Post hoc analysis of the dose response within each cell fraction group is summarized in Table I, which is visually reflected in Fig. 1. Of note, the number of cells in the control groups were seeded equally, however because the exhibited images display cell colonies which were allowed to grow for three weeks, the observed phenomenon of the $\mathrm{ALDH}^{\text {high }}$ group (the CSC group) appearing to have more cells is explained by the fact that these cells divide faster than tumor stromal/bulk cells and thus this group grew more over the three week period than the other two groups. There was a statistically significant interaction between the effects of PRP-1 dose and cell population on anchorage independent colony growth $(\mathrm{F}(12,21)=4.608 ; \mathrm{P}=0.0011)$. Simple main effects analysis was carried out, and significant differences in colony growth were observed between each colony cell type at a specified PRP-1 dose. At $0.05 \mu \mathrm{g} / \mathrm{ml}$ PRP-1, the mean growth of $\mathrm{ALDH}^{\text {low }} \mathrm{JJ} 012$ cells was significantly lower than that of $\mathrm{ALDH}^{\text {high }}$ cells $(22.16 \pm 20.59 ; \mathrm{P}=0.0334)$. At a dose of $0.50 \mu \mathrm{g} / \mathrm{ml}$ PRP-1, the mean growth of JJ012 bulk cells was significantly lower compared with that of ALDH $^{\text {high }}$ cells $(20.82 \pm 20.32 ; \mathrm{P}=0.0471)$. At a PRP-1 dose of $1 \mu \mathrm{g} / \mathrm{ml}$, no significant differences in mean growth were observed between any of the cell colony groups. At $5 \mu \mathrm{g} / \mathrm{ml}$ PRP-1, the mean growth of JJ012 bulk cells $(28.03 \pm 20.59$; $\mathrm{P}=0.0068)$ and $A L D H^{\text {high }}$ cells $(20.77 \pm 20.58 ; \mathrm{P}=0.0477)$ was significantly lower than that of $\mathrm{ALDH}^{\text {low }}$ cells. At a dose of $10 \mu \mathrm{g} / \mathrm{ml}$, the mean growth of JJ012 bulk cells (35.21 $\pm 20.59 ; \mathrm{P}=0.0009)$ and $\mathrm{ALDH}^{\text {high }}$ cells $(29.28 \pm 20.59$; 
Table II. Post-Hoc Tukey's analysis of spheroid growth.

\begin{tabular}{lcrr}
\hline Comparison & Mean difference & 95\% confidence interval of difference & P-value \\
\hline 0.0 vs. 0.05 & 30.15 & 22.97 to 37.34 & $<0.0001$ \\
0.0 vs. 0.5 & 61.57 & 54.39 to 68.76 & $<0.0001$ \\
0.0 vs. 1.0 & 64.17 & 56.99 to 71.35 & $<0.0001$ \\
0.0 vs. 5.0 & 80.85 & 73.67 to 88.03 & $<0.0001$ \\
0.0 vs. 10 & 92.93 & 85.74 to 100.1 & $<0.0001$ \\
0.0 vs. 20 & 96.18 & 88.99 to 103.4 & $<0.0001$ \\
0.05 vs. 0.5 & 31.42 & 24.24 to 38.60 & $<0.0001$ \\
0.05 vs. 1.0 & 34.02 & 26.83 to 41.20 & $<0.0001$ \\
0.05 vs. 5.0 & 50.70 & 43.51 to 57.88 & $<0.0001$ \\
0.05 vs. 10 & 62.77 & 55.59 to 69.96 & $<0.0001$ \\
0.05 vs. 20 & 66.03 & 58.84 to 73.21 & $<0.0001$ \\
0.5 vs. 1.0 & 2.598 & -4.586 to 9.782 & 0.9075 \\
0.5 vs. 5.0 & 19.28 & 12.09 to 26.46 & $<0.0001$ \\
0.5 vs. 10 & 31.35 & 24.17 to 38.54 & $<0.0001$ \\
0.5 vs. 20 & 27.42 to 41.79 & $<0.0001$ \\
1.0 vs. 5.0 & 34.61 & 9.496 to 23.86 & $<0.0001$ \\
1.0 vs. 10 & 16.68 & 21.57 to 35.94 & $<0.0001$ \\
1.0 vs. 20 & 28.76 & 24.82 to 39.19 & $<0.0001$ \\
5.0 vs. 10 & 32.01 & 4.892 to 19.26 & 0.0002 \\
5.0 vs. 20 & 12.08 & 8.144 to 22.51 & $<0.0001$ \\
10 vs. 20 & 15.33 & -3.932 to 10.44 & 0.7781 \\
\hline
\end{tabular}

$\mathrm{P}=0.0048)$ was significantly lower than that of $\mathrm{ALDH}^{\text {low }}$ cells. Finally, at $20 \mu \mathrm{g} / \mathrm{ml}$ PRP-1, the mean growth of JJ012 bulk cells $(38.27 \pm 20.59 ; \mathrm{P}=0.0004)$ and $\mathrm{ALDH}^{\text {high }}$ cells (30.66 $\pm 20.59 ; \mathrm{P}=0.0032)$ was significantly lower than that of $\mathrm{ALDH}^{\text {low }}$ cells.

Considering the aforementioned effect of PRP-1 in inhibiting anchorage independent growth in chondrosarcoma cell colonies, and its previously demonstrated cytostatic effects on chondrosarcoma S phase arrest, the effects of PRP-1 on spheroid growth were subsequently investigated. Spheroids were successfully cultured following a well-established spheroid formation assay (described in Materials and methods), indicating the presence and proliferation of CSCs in a hostile anchorage independent, serum-free environment. Spheroids were formed in four separate experiments; the last experiment utilized a dose-response technique, which included identical doses of PRP-1 to those used in the aforementioned colony formation experiment. Spheroid growth was qualitatively and quantitatively evaluated, and a significant decrease in growth was observed with increasing doses of PRP-1 (Fig. 2A). One-way ANOVA was conducted to determine the effect of PRP-1 dosage on spheroid growth in the bulk JJ012 cell population (Fig. 2B; Table II). A statistically significant decrease in spheroid growth was observed with increasing doses of PRP-1 $(\mathrm{F}(6,28)=476.7 ; \mathrm{P}<0.0001)$. Furthermore, Tukey's post hoc multiple comparisons test highlighted significant differences between all doses (Table II, visually reflected in Fig. 2), except between 0.5 and $1 \mathrm{mg} / \mathrm{ml}(2.598 \pm 7.184 ; \mathrm{P}=0.9075)$, and between 10 and $20 \mathrm{mg} / \mathrm{ml}$ PRP-1 (3.252 $\pm 7.188 ; \mathrm{P}=0.7781)$.
Sarcoma spheroids were grown, filtered into single cell suspensions, transferred to a 2D flask for monolayer culture, and their self-renewal properties were established through the successful re-growth of spheroids from cells of the monolayer (Fig. 3A). By breaking the first round spheroid into single cell suspensions and then forming the second round spheroids from these single cells, this methodology ensures that the second round spheroids are forming from the original first round spheroids and allows us to isolate the property of self-renewal. Utilization of an established spheroid self-renewal assay confirmed the presence and self-renewal capacity of CSCs. Size measurements of $n=4$ spheroids revealed that self-renewed spheroids were consistently larger than those from the original culture (Table III; visually represented in Fig. 3). In terms of area measurement, the self-renewed spheroids were consistently more than double the mean size of the original spheroids.

Mesenchymal stem cell markers CD44, STRO-1 and STAT3 in chondrosarcoma spheroids. Western blotting was performed to confirm the presence of mesenchymal stem cells within the chondrosarcoma cell and spheroid populations. The mesenchymal and CSC biomarkers CD44 and STRO-1 were identified in chondrosarcoma CSCs (Fig. 3B). The mean relative OD values for STRO1, CD44 and STAT3 $(\mathrm{n}=4$ each) were $2.33(\mathrm{P}<0.54), 2.34(\mathrm{P}<0.34)$ and 2.34 $(\mathrm{P}<0.26)$, respectively (STAT3 data not shown). Thus, no significant difference in the expression of CSC biomarkers was revealed between the PRP-1-treated and untreated groups. 
A

First round

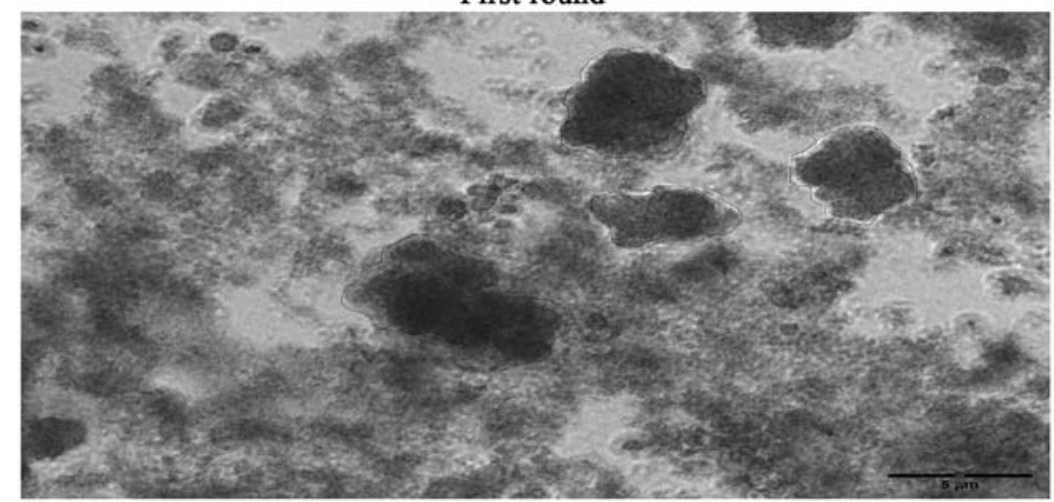

Second round

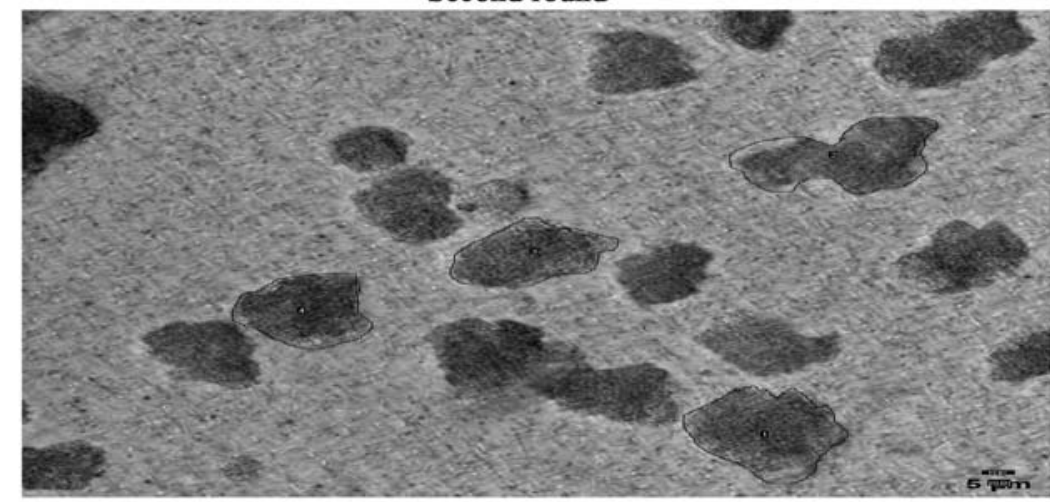

B

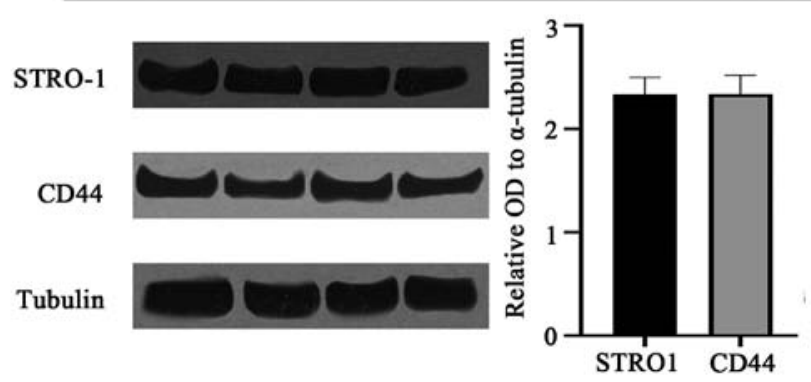

Figure 3. Chondrosarcoma spheroid self-renewal assay. (A) Spheroids grown during initial spheroid assay demarcated as 'First Round' compared to self-renewed spheroids demarcated as 'Second Round'. Magnification, x40. (B) Western blot analysis of chondrosarcoma CSCs displaying the presence of and relative OD of STRO-1 and CD44 measured against housekeeping protein $\alpha$-tubulin. Magnification, x20. OD, optical density; CSC, cancer stem cells; $\mathrm{CD}$, cluster of differentiation.

PRP-1 does not significantly alter the apoptotic or late apoptotic/necrotic stages of JJO12 bulk cells. Following treatment with PRP-1, an Annexin V/PI assay was performed to flow cytometrically investigate the mechanism by which CSC and stromal cell death occurs in chondrosarcoma cells. Exposure to PRP-1 did result in cell death but did not alter the percentage of cells in the apoptotic (Annexin $\mathrm{V}^{+}$) or late apoptotic/necrotic (Annexin $\mathrm{V}^{+} \mathrm{PI}^{+}$) stages (Fig. 4); $\mathrm{n}=3$ separate cultures per group.

\section{Discussion}

The observed reduction in chondrosarcoma cell colony formation following PRP-1 administration confirms its ability to interfere with anchorage independent growth, a component of metastatic potential that is inherent to the CSC population. In the present study, the greatest decrease in colony formation was observed in the bulk JJ012 cell group, followed closely by the $\mathrm{ALDH}{ }^{\text {high }} \mathrm{CSC}$ population. This confirms that PRP-1 selectively targets CSCs, but also effectively inhibits stromal cell tumor growth (Fig. 1; Table I). A reduction in tumor stromal cells is further supported by the decreased expansion of the $\mathrm{ALDH}^{\text {low }}$ non-CSC population, albeit to a lesser degree than that observed in the bulk and CSC populations. In summary, the ALDH ${ }^{\text {high }}$ and JJ012 bulk cell populations have a higher proliferative capacity than the $\mathrm{ALDH}^{\text {low }}$ population. Low doses of PRP-1 did not significantly suppress ALDH ${ }^{\text {high }}$ or JJ012 bulk population growth, therefore ALDH ${ }^{\text {low }}$ displayed relatively less growth at these doses. However, greater suppression of ALDH ${ }^{\text {high }}$ and JJ012 bulk cells was observed with increasing doses of PRP-1, which indicates selective inhibition of CSCs. Compared with other chemotherapeutic approaches, this result is favorable and unique, as PRP-1 not only decreased the CSC population, but to an extent, also reduced the proportion of CSCs within the stromal population. In the clinic, selective targeting of CSCs in chemo- and 
Table III. Sarcosphere self-renewal assay.

\begin{tabular}{lcccc}
\hline Round & Area $\left(\mathrm{mm}^{3}\right)$ & Mean diameter $(\mathrm{mm})$ & Min diameter $(\mathrm{mm})$ & Max diameter $(\mathrm{mm})$ \\
\hline 1 & 32.64 & 81.98 & 30 & 212 \\
1 & 22.26 & 89.02 & 35 & 244 \\
1 & 16.66 & 116.88 & 46 & 255 \\
1 & 12.76 & 113.80 & 49 & 235 \\
2 & 471.36 & 190.76 & 158 & 232 \\
2 & 469.08 & 192.83 & 157 & 235 \\
2 & 341.43 & 190.58 & 154 & 231 \\
2 & 345.64 & 184.40 & & \\
\hline
\end{tabular}

Round 1, original spheroids; Round 2, self-renewed spheroids.

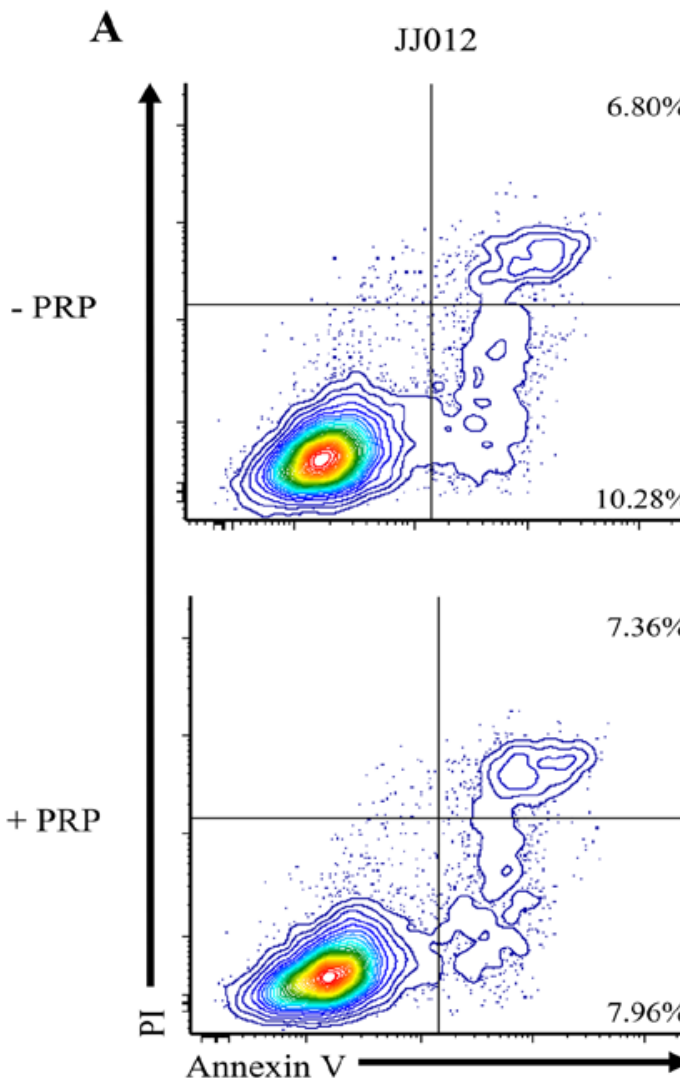

B

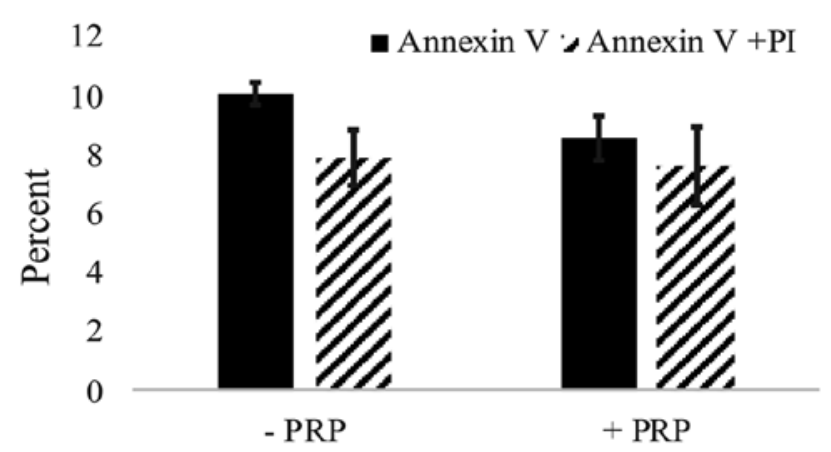

Figure 4. Annexin V/Propidium Iodide apoptosis assay on chondrosarcoma CSCs. (A) Flow cytometric analysis of chondrosarcoma CSCs as control (-PRP) vs. treated (+PRP). (B) Comparison of apoptotic $\left(\right.$ Annexin $\mathrm{V}^{+}$) and late apoptotic/necrotic (Annexin $\mathrm{V}^{+} \mathrm{PI}^{+}$) cell populations in control CSCs (-PRP) and those treated with PRP-1 (+PRP). CSC, cancer stem cells.

radio-resistant chondrosarcomas is a great barrier to effective patient management, though the findings of the present study indicate that the use of PRP-1 shows promise to overcome this obstacle. Once CSC death is induced (and their source of propagation has been diminished), tumor stromal cells are susceptible to chemo- and/or radiotherapeutic eradication (35).

Of note, $20 \mu \mathrm{g} / \mathrm{ml}$ was found to be the optimal dose of PRP-1 for reducing cell colony formation, which is supported by post hoc analysis (Fig. 1C). Collectively, the present study reports that low micromolar concentrations of PRP-1 inhibit the proliferation of chondrosarcoma CSCs.
To confirm the presence of CSCs, western blot analysis was used to identify the mesenchymal and CSC markers STRO-1, CD44 and STAT3 $(36,37)$. The results indicate the presence of these markers with comparable band densities and almost identical average ODs between the three markers of interest (Fig. 4). The consistent expression of these markers confirms the presence of CSCs within spheroids, and subsequently, that CSCs are the primary contributors to spheroid structure and survival (20).

Furthermore, the observed reduction in spheroid growth after PRP-1 treatment indicates its ability to target CSCs, and 
also to penetrate the outer proliferative layer and microenvironment of the tumor-derived 3D culture in order to reach the CSC-containing middle layer (38). Spheroids are an accepted in vitro archetype considered to be analogous to animal models, and require the active presence of CSCs for formation and growth (39). Spheroids allow for the formation of a tumor microenvironment comparable to that of in vivo tumors. The present study revealed a reduction in spheroid growth following PRP-1 administration, with a maximum reductive dose of $20 \mu \mathrm{g} / \mathrm{ml}$ resulting in spheroid growth at only $4.82 \%$ of control growth. Compared with a significant reduction in cell colony formation, a higher dose of PRP-1 was required for maximum spheroid growth reduction. This likely reflects the need for PRP-1 infiltration into the 3D spheroid microenvironment, while cell colonies do not exhibit this same structural resilience. This may be secondary to the central location of CSCs within the spheroid (and in the in vivo tumor), whereas colonies and cells cultured in a 2D monolayer do not exhibit such a spherically dense and not easily penetrated growth pattern (40).

Notably, spheroid self-renewal occurred under growth-restrictive conditions, suggesting that spheroids contain a small subpopulation of self-renewing primitive/progenitor cells. This self-renewal capacity is archetypally unique to CSCs, non-neoplastic stem cells, and other cells demonstrating stemness (41). With respect to average surface area measurements, self-renewed spheroids were $>2$ times the size of naively cultured spheroids. This may be due to the resilience of CSCs in the self-renewed population, along with readily available mRNA coding transcription and growth factors, which are synthesized during culture of the original spheroids. In this context, future directions may include confirming the presence of progenitor markers in spheroid lysates derived from self-renewed 3D cultures and determining whether PRP-1 directly inhibits this property of self-renewal.

Annexin V/PI analysis revealed an overall decrease in spheroid viability following PRP-1 treatment and highlighted that cell death was not occurring by apoptosis or late apoptosis/necrosis. This finding is consistent with a previous study, where no significant changes in apoptosis was observed in JJ012 cells treated with PRP-1; however, the cells were found to accumulate in the $S$ phase of the cell cycle, indicating the cytostatic effects of PRP-1 (26). Further investigations may identify the exact mechanism by which PRP-1 promotes cell death. Spheroids have reportedly been used to investigate anoikis in anchorage independent tumor growth, as was also conducted in the present study. Future directions should aim to identify whether anoikis is partially or fully responsible for PRP-1-associated cell death in chondrosarcoma (10).

The present study is not without limitation. Flow cytometric analysis of spheroids is not always feasible, as 3D cultures are often too large to enter the flow cytometer, limiting Annexin V/PI analysis to isolated CSCs only. Because spheroid growth in chondrosarcoma is not fully understood, imaging and establishment of spheroid characteristics was considered to be of greater importance.

Impending goals include elucidating the molecular mechanism by which PRP-1 induces CSC death. Additionally, as PRP-1-associated cell signaling modifications are more clearly understood, the use of animal models may become more clinically significant. Though 3D spheroid models are considered to be analogous to in vivo conditions, the use of animal models will not only elucidate a consistent effect in a living organism but will also allow for a basic understanding of the coexistent effects of PRP-1 in non-neoplastic tissues.

The results of the current study highlight the inhibitory effects of PRP-1 on anchorage independent colony growth, and in turn, the malignant potential of chondrosarcoma CSCs. These findings indicate that PRP-1 effectively reduces CSC sustainability in a reliable spheroid chondrosarcoma tumor model, which is significant for the development of novel clinical approaches and biologic agents used to manage chondrosarcoma.

The use of PRP-1 to treat metastatic chondrosarcoma exhibits potential, notably decreasing or perhaps entirely eliminating tumors when combined with current management strategies, which warrants future investigation in a murine model. If equally effective in a clinical setting, PRP-1 may hypothetically decrease the morbidity and mortality associated with chondrosarcoma. Further studies are required to improve our understanding of the effects of PRP-1 on both neoplastic and non-neoplastic tissues, the latter of which will be accomplished using xenograft orthotopic transplantation of chondrosarcoma spheroids into immunocompromised mice. Therefore, it behooves us to evaluate whether PRP-1 decreases the size of the primary tumor and prevents spontaneous metastasis to the lungs. Additional ongoing experiments include those which will improve our understanding of the cellular and molecular mechanisms by which PRP-1 induces CSC death.

\section{Acknowledgements}

The authors would like to thank Dr Mark Brown (University of Miami Department of Orthopaedic Surgery).

\section{Funding}

The present study was supported in part by a gift from the Ratcliffe Foundation to the Miami Center of Orthopedic Research and Education (CORE).

\section{Availability of data and materials}

All data generated or analyzed during this study are included in this published article.

\section{Authors' contributions}

CJG and KG designed the study. CJG, AKH, AM, BB, AS, SS, $\mathrm{JB}, \mathrm{SAC}$ and $\mathrm{KG}$ conducted the experiments and/or analyzed the data. CJG and KG prepared the initial manuscript. CJG, $\mathrm{AKH}, \mathrm{BB}$ and $\mathrm{AS}$ prepared the figures and tables. CJG, $\mathrm{AKH}$, $\mathrm{AM}, \mathrm{SAC}$ and $\mathrm{KG}$ critically reviewed and revised the manuscript for important intellectual content. All authors read and approved the final manuscript.

\section{Ethics approval and consent to participate}

Not applicable. 


\section{Patient consent for publication}

Not applicable.

\section{Competing interests}

The authors declare that they have no competing interests.

\section{References}

1. Karpik M and Reszec J: Low grade chondrosarcoma-epidemiology, diagnosis, treatment. Ortop Traumatol Rehabil 20: 65-70, 2018

2. Boehme KA, Schleicher SB, Traub F and Rolauffs B: Chondrosarcoma: A rare misfortune in aging human cartilage? The role of stem and progenitor cells in proliferation, malignant degeneration and therapeutic resistance. Int J Mol Sci 19: 311, 2018.

3. Chow WA: Chondrosarcoma: Biology, genetics, and epigenetics. F1000Res 7: F1000 Faculty Rev-1826, 2018.

4. Leddy LR and Holmes RE: Chondrosarcoma of bone. Cancer Treat Res 162: 117-130, 2014.

5. Mery B, Espenel S, Guy JB, Rancoule C, Vallard A, Aloy MT, Rodriguez-Lafrasse $\mathrm{C}$ and Magné N: Biological aspects of chondrosarcoma: Leaps and hurdles. Crit Rev Oncol Hematol 126: 32-36, 2018

6. Andreou D, Ruppin S, Fehlberg S, Pink D, Werner M and Tunn PU: Survival and prognostic factors in chondrosarcoma: Results in 115 patients with long-term follow-up. Acta Orthop 82: 749-755, 2011.

7. Wan L, Tu C, Li S and Li Z: Regional lymph node involvement is associated with poorer survivorship in patients with chondrosarcoma: A SEER analysis. Clin Orthop Relat Res 477: 2508-2518, 2019.

8. Nie Z, Lu Q and Peng H: Prognostic factors for patients with chondrosarcoma: A survival analysis based on the Surveillance, Epidemiology, and End Results (SEER) database (1973-2012). J Bone Oncol 13: 55-61, 2018.

9. Song K, Song J, Chen F, Lin K, Ma X and Jiang J: Does resection of the primary tumor improve survival in patients with metastatic chondrosarcoma? Clin Orthop Relat Res 477: 573-583, 2019.

10. Colella G, Fazioli F, Gallo M, De Chiara A, Apice G, Ruosi C, Cimmino A and de Nigris F: Sarcoma spheroids and organoids-promising tools in the Era of personalized medicine. Int J Mol Sci 19: 615, 2018.

11. Brown HK, Tellez-Gabriel M and Heymann D: Cancer stem cells in osteosarcoma. Cancer Lett 386: 189-195, 2017.

12. Rodriguez R, Rubio R and Menendez P: Modeling sarcomagenesis using multipotent mesenchymal stem cells. Cell Res 22 : 62-77, 2012.

13. Hanahan D and Weinberg RA: The hallmarks of cancer. Cell 100: 57-70, 2000 .

14. Fouad YA and Aanei C: Revisiting the hallmarks of cancer. Am J Cancer Res 7: 1016-1036, 2017.

15. Ishiguro T, Ohata H, Sato A, Yamawaki K, Enomoto T and Okamoto K: Tumor-derived spheroids: Relevance to cancer stem cells and clinical applications. Cancer Sci 108: 283-289, 2017.

16. Guo X, Chen Y, Ji W, Chen X, Li C and Ge R: Enrichment of cancer stem cells by agarose multi-well dishes and 3D spheroid culture. Cell Tissue Res 375: 397-408, 2019.

17. Mehta P, Novak C, Raghavan S, Ward M and Mehta G: Self-renewal and CSCs in vitro enrichment: Growth as floating spheres. Methods Mol Biol 1692: 61-75, 2018

18. Ma R, Mandell J, Lu F, Heim T, Schoedel K, Duensing A, Watters RJ and Weiss KR: Do patient-derived spheroid culture models have relevance in chondrosarcoma research? Clin Orthop Relat Res: May 19,2020.doi: 10.1097/CORR.0000000000001317. (Epub ahead of print).

19. Fujii H, Honoki K, Tsujiuchi T, Kido A, Yoshitani K and Takakura Y: Sphere-forming stem-like cell populations with drug resistance in human sarcoma cell lines. Int $\mathbf{J}$ Oncol 34 1381-1386, 2009

20. Gao S, Shen J, Hornicek F and Duan Z: Three-dimensional (3D) culture in sarcoma research and the clinical significance. Biofabrication 9: 032003, 2017.
21. Gibbs CP, Kukekov VG, Reith JD, Tchigrinova O, Suslov ON, Scott EW, Ghivizzani SC, Ignatova TN and Steindler DA: Stem-like cells in bone sarcomas: Implications for tumorigenesis. Neoplasia 7: 967-976, 2005.

22. Tang QL, Zhao ZQ, Li JC, Liang Y, Yin JQ, Zou CY, Xie XB, Zeng YX, Shen JN, Kang T and Wang J: Salinomycin inhibits osteosarcoma by targeting its tumor stem cells. Cancer Lett 311: 113-121, 2011.

23. Galoyan AA, Shakhlamov VA, Aghajanov MI and Vahradyan HG: Hypothalamic proline-rich polypeptide protects brain neurons in aluminum neurotoxicosis. Neurochem Res 29: 1349-1357, 2004.

24. Galoian K, Abrahamyan S, Chailyan G, Qureshi A, Patel P, Metser G, Moran A, Sahakyan I, Tumasyan N, Lee A, et al: Toll like receptors TLR1/2, TLR6 and MUC5B as binding interaction partners with cytostatic proline rich polypeptide 1 in human chondrosarcoma. Int J Oncol 52: 139-154, 2018.

25. Galoian K, Luo S, Qureshi A, Patel P, Price R, Morse AS, Chailyan G, Abrahamyan S and Temple HT: Effect of cytostatic proline rich polypeptide-1 on tumor suppressors of inflammation pathway signaling in chondrosarcoma. Mol Clin Oncol 5: 618-624, 2016.

26. Galoian KA, Temple TH and Galoyan A: Cytostatic effect of novel mTOR inhibitor, PRP-1 (galarmin) in MDA 231 (ER-) breast carcinoma cell line. PRP-1 inhibits mesenchymal tumors. Tumour Biol 32: 745-751, 2011.

27. Galoian K, Scully S and Galoyan A: Myc-oncogene inactivating effect by proline rich polypeptide (PRP-1) in chondrosarcoma JJ012 cells. Neurochem Res 34: 379-385, 2009.

28. Galoian K, Scully S, McNamara G, Flynn P and Galoyan A: Antitumorigenic effect of brain proline rich polypeptide-1 in human chondrosarcoma. Neurochem Res 34: 2117-2121, 2009.

29. Galoian K, Qureshi A, Wideroff G and Temple HT: Restoration of desmosomal junction protein expression and inhibition of $\mathrm{H} 3 \mathrm{~K} 9$-specific histone demethylase activity by cytostatic proline-rich polypeptide-1 leads to suppression of tumorigenic potential in human chondrosarcoma cells. Mol Clin Oncol 3: 171-178, 2015.

30. Hoyt AK, Moran A, Granger C, Sedani A, Saigh S, Brown J and Galoian KA: PRP1 significantly decreases the ALDHhigh cancer stem cell population and regulates the aberrant $\mathrm{Wnt} / \beta$-catenin pathway in human chondrosarcoma JJ012 cells. Oncol Rep 42: 103-114, 2019.

31. Horibata S, Vo TV, Subramanian V, Thompson PR and Coonrod SA: Utilization of the soft agar colony formation assay to identify inhibitors of tumorigenicity in breast cancer cells. J Vis Exp: e52727, 2015.

32. Cesarz Z and Tamama K: Spheroid culture of mesenchymal stem cells. Stem Cells Int 2016: 9176357, 2016

33. Dong G, Wang S, Ge Y, Deng Q, Cao Q, Wang Q, Shang Z, OuYang W, Li J, Liu C, et al: Serum-free culture system for spontaneous human mesenchymal stem cell spheroid formation. Stem Cells Int 2019: 6041816, 2019.

34. Rieger AM, Nelson KL, Konowalchuk JD and Barreda DR: Modified annexin V/propidium iodide apoptosis assay for accurate assessment of cell death. J Vis Exp: 2597, 2011.

35. Whelan JS and Davis LE: Osteosarcoma, chondrosarcoma, and chordoma. J Clin Oncol 36: 188-193, 2018.

36. Mas A, Prusinski L, Yang Q, Diaz-Gimeno P, Stone L, Diamond MP, Simón C and Al-Hendy A: Role of Strol ${ }^{+} / \mathrm{CD}_{4} 4^{+}$ stem cells in myometrial physiology and uterine remodeling during pregnancy. Biol Reprod 96: 70-80, 2017.

37. Galoczova M, Coates P and Vojtesek B: STAT3, stem cells, cancer stem cells and p63. Cell Mol Biol Lett 23: 12, 2018.

38. Fang $\mathrm{Y}$ and Eglen RM: Three-dimensional cell cultures in drug discovery and development. SLAS Discov 22: 456-472, 2017.

39. Song L, Yuan X, Jones Z, Zhou Y, Ma T and Li Y: Assembly of human stem cell-derived cortical spheroids and vascular spheroids to model 3-D brain-like tissues. Sci Rep 9: 5977, 2019.

40. Leek R, Grimes DR, Harris AL and McIntyre A: Methods: Using three-dimensional culture (Spheroids) as an in vitro model of tumour hypoxia. Adv Exp Med Biol 899: 167-196, 2016.

41. Huang G, Ye S, Zhou X, Liu D and Ying QL: Molecular basis of embryonic stem cell self-renewal: From signaling pathways to pluripotency network. Cell Mol Life Sci 72: 1741-1757, 2015. 